\title{
TCF3 inhibits F9 embryonal carcinoma growth by the down-regulation of Oct4
}

\author{
GUIMIAO LIN ${ }^{1,2}$, LIJUAN ZHAO ${ }^{1}$, FENG YIN ${ }^{2}$, RONGFENG LAN ${ }^{2}$, LIANBO LI $^{2}$, \\ XIAOMING ZHANG ${ }^{2}$, HUI ZHANG ${ }^{2}$ and BAOXUE YANG ${ }^{1,3,4}$
}

\author{
${ }^{1}$ Department of Pathophysiology, Norman Bethune Medical School, Jilin University, Changchun 130021; \\ ${ }^{2}$ Laboratory of Chemical Genomics, School of Chemical Biology and Biotechnology, Peking University Shenzhen \\ Graduate School, Shenzhen 518055; ${ }^{3}$ Department of Pharmacology, School of Basic Medical Sciences, Peking University \\ and ${ }^{4}$ Key Laboratory of Molecular Cardiovascular Sciences, Ministry of Education, Beijing 100191, P.R. China
}

Received April 29, 2011; Accepted May 30, 2011

DOI: 10.3892/or.2011.1376

\begin{abstract}
T-cell factor 3 (TCF3), a downstream effector of Wnt signaling in embryonic stem (ES) cells, plays an important role in pluripotent self-renewal and proliferation. Loss of TCF3 delays the differentiation of mouse ES cells. The purpose of this study was to investigate the effect of TCF3 on embryonal carcinoma (EC). The mouse F9 EC cell line and a tumor-bearing mouse model were used to evaluate the anti-EC tumor effects of TCF3 in vitro and in vivo, respectively. The overexpression of TCF3 significantly inhibited proliferation, colony-forming and migration in F9 EC cells by approximately 30,45 and $30 \%$, respectively. The in vivo mouse model showed that the overexpression of TCF3 significantly reduced tumor volume (36.4\%) and tumor weight (34.8\%), malignancy progression and local infiltration and prolonged the life span of tumor-bearing mice. Overexpression of TCF3 significantly down-regulated Oct4 expression in the F9 EC cells. The results indicate that TCF3 is an inhibitor of the malignant phenotypes of embryonal carcinoma through the regulation of Oct4 expression.
\end{abstract}

\section{Introduction}

Embryonal carcinoma (EC) is a highly malignant tumor and occurs primarily in young adults. EC cells, which are malignant stem cells of teratoma, have morphological and biochemical properties similar to embryonic stem (ES) cells (1). In ES cells, the factors Oct4, Sox 2 and Nanog form a regulatory circuitry to maintain pluripotency and self-renewal (2). The Wnt pathway is involved in the self-renewal and

Correspondence to: Dr Baoxue Yang, Department of Pharmacology, School of Basic Medical Sciences, Peking University, Beijing 100191, P.R. China

E-mail: baoxue@bjmu.edu.cn

Key words: embryonal carcinoma, F9 cells, Oct4, overexpression, T-cell factor 3 pluripotency of ES cells, for which the mechanism remains unclear (3-5).

T-cell factor (TCF) proteins, the terminal factors of the Wnt pathway, possess a highly conserved HMG domain and an amino-terminal $\beta$-catenin interaction domain. When Wnt-stabilized $\beta$-catenin is accumulated, TCF proteins promote the transcription of downstream targets $(6,7)$. In the absence of stabilized $\beta$-catenin, TCF proteins function as transcriptional repressors by interacting with co-repressor proteins, such as CtBP and Groucho (8-10). It has been shown that T-cell factor 3 (TCF3) forms a repressor complex with TLE2 (Groucho2) $(9,11,12)$ and co-occupies the promoters throughout the genome with Oct4 and Nanog, which is an integral part of the core regulatory circuitry in ES cells with pluripotency (13). Loss of TCF3 or activation of the Wnt pathway increases the expression of Oct4, Nanog and other ES transcription factors and provokes stem cell resistance to differentiation (12-14). In addition, ablation of TCF3 in ES cells was found to maintain cell self-renewal in the absence of exogenous leukemia inhibitory factor (LIF) and delayed the response to differentiation stimuli (14). In addition, the proliferation rates of TCF3 null ES cells were significantly decreased by inhibiting Jak/Stat3 activity (15). These findings identify TCF3 as a cell-intrinsic inhibitor of pluripotent cell self renewal by limiting the steady-state levels of many selfrenewal factors (15).

The purpose of this study was to investigate whether TCF3 affects EC development and progression. TCF3 was found to inhibit mouse F9 EC cell growth, proliferation and migration, suggesting a critical role of TCF3 in EC development and progression. TCF3 also inhibited the growth and infiltration of transplanted tumors and prolonged the life span of tumorbearing mice. The results also showed that TCF3 inhibited EC through the regulation of Oct4 expression.

\section{Materials and methods}

Cell culture. Mouse embryonal carcinoma F9 cells, human embryonic kidney 293T cells, mouse embryonic fibroblast NIH3T3 cells, mouse embryonic fibroblast MEF cells and 
human cervical carcinoma HeLa cells were purchased from the American Type Culture Collection (ATCC). Mouse embryonic stem cells (mES) were kindly provided by $\mathrm{Dr}$ Zhigang Lu (Laboratory of Chemical Genomics, Peking University Shenzhen Graduate School). F9-control and F9-TCF3 EC cells were derived from F9 cells established at the Laboratory of Chemical Genomics, Peking University Shenzhen Graduate School. All cells were cultured in Dulbecco's modified Eagle's medium (DMEM) (Hyclone), supplemented with 10\% fetal bovine serum (FBS) (Hyclone), $100 \mu \mathrm{g} / \mathrm{ml}$ penicillin (Ameresco) and $100 \mu \mathrm{g} / \mathrm{ml}$ streptomycin (Ameresco). Cells were maintained at $37^{\circ} \mathrm{C}$ in a humidified atmosphere with $5 \% \mathrm{CO}_{2}$.

Plasmid construction and retrovirus package. Mouse TCF3 cDNA (GenBank no. BC128306.1) was PCR amplified from the pCR-BluntII-TOPO-mouse TCF3 plasmid (Open Biosystem) using primers 5'-ATATAGGATCCATGCCCCA GCTCGGTGGT-3' (sense) and 5'-GCGCCGAATTCTAATGC TTCCTTTGTGTTTC-3' (antisense), and subsequently cloned into the BamHI/EcoRI sites of the pMSCV-puro-3Flag-3HA retrovirus vector that contains tri-Flag and tri-HA tag fused to the $\mathrm{N}$ terminus of inserted protein, modified from the pMSCV-puro (Clontech). The complete reading frame of the new construct was verified by automated sequencing and the recombinant plasmids were purified. Exponentially growing 293T cells were seeded at $8 \times 10^{6}$ cells per $100-\mathrm{mm}$ dish one day prior to transfection. pMSCV-3Flag-3HA empty vectors or pMSCV-3Flag-3HA-TCF3 vectors were introduced into $293 \mathrm{~T}$ cells, respectively, together with the package vector pCL-Eco using Lipofectamine ${ }^{\mathrm{TM}} 2000$ transfection reagent (Invitrogen) following the manufacturer's instructions. Cells were then incubated at $37^{\circ} \mathrm{C}$ in $5 \% \mathrm{CO}_{2}$ for $6 \mathrm{~h}$, and the medium was then replaced with fresh DMEM medium with $10 \%$ FBS. The virus was harvested $24 \mathrm{~h}$ later.

Establishment of a cell line which stably expresses TCF3. For virus infection, $2 \times 10^{6} \mathrm{~F} 9$ cells were seeded on $100-\mathrm{mm}$ dishes that were pre-coated with $0.1 \%$ gelatin for $4 \mathrm{~h}$ before usage and allowed to grow exponentially. Virus-containing medium derived from the vector-transfected $293 \mathrm{~T}$ cells was filtered through a $0.45-\mu \mathrm{m}$ cellulose acetate filter (Millipore) and added to the medium of the F9 cells. Polybrene (Sigma) was added $(4 \mu \mathrm{g} / \mathrm{ml})$ to assist infection. Virus-infected F9 cells were selected with puromycin $(1 \mu \mathrm{g} / \mathrm{ml})$ (Sigma). Both F9-control (infected with empty vector) and F9-TCF3 (stably expressed 3Flag-3HA-TCF3) cell lines were confirmed by immunoblotting using anti-Flag and anti-TCF3 antibodies.

Cell proliferation assay. Cell proliferation was assayed by seeding $2.5 \times 10^{4}$ cells per well in a 6 -well plate (day 0 ). On days 1, 2, 3 and 4, cells were washed with PBS twice, harvested by trypsination and counted using a hemocytometer. All assays were carried out in sextuplicate. Cell proliferation was also measured by MTT [3-(4, 5-dimethylthiazol-2-yl)2,5-diphenyltetrazolium bromide] (Sigma) assay. F9-control and F9-TCF3 cells were seeded in a 96-well plate at a density of $1 \times 10^{4}$ cells per well (day 0). On days 1,2 and 3, $20 \mu 1$ of $5 \mathrm{mg} / \mathrm{ml} \mathrm{MTT}$ in PBS was added, and the cells were subsequently incubated for $4 \mathrm{~h}$ at $37^{\circ} \mathrm{C}$ in $5 \% \mathrm{CO}_{2}$. Cells were then washed twice with PBS, and the precipitate was solublized in $150 \mu \mathrm{l}$ of $100 \%$ dimethylsulfoxide (Sigma) by shaking for 5 min. Absorbance was measured using a microplate reader (Bio-Rad, Richmond, CA) at a wavelength of $570 \mathrm{~nm}$. All experiments were carried out in sextuplicate.

Cell colony formation assay. A two-layer soft agar system was used in this assay. Briefly, $1 \times 10^{3}$ F9-control or F9-TCF3 EC cells were resuspended in medium ( $1 \mathrm{ml}$ per well) containing $0.3 \%$ low-melting agarose, and then layered on top of a solidified medium ( $1.4 \mathrm{ml}$ per well) containing $0.6 \%$ agarose. The plates were incubated at $37^{\circ} \mathrm{C}$ in $5 \% \mathrm{CO}_{2}$ for 10 days. Colonies were subjected to a microscopic test and imaged using Zeiss Axio observer A1 microscopy. The total numbers of colonies $>50$ cells were determined. All experiments were carried out in sextuplicate.

Cell migration assay. Cells were plated onto 12-well plates at a density of $8 \times 10^{4}$ cells/well. After forming a monolayer, cells were wounded by manual scraping with a $200-\mu \mathrm{m}$ micropipette tip. The culture medium was then replaced with fresh, serumfree medium. The wound repair process by migrating cells was monitored by measuring the gap and imaged using Zeiss Axio observer A1 microscopy. The gap distance was measured at 0 and $24 \mathrm{~h}$. All experiments were carried out in triplicate.

Tumor xenograft formation and histological analysis. BALB/C mice (20 per group) $\sim 6$ weeks of age (body weight, $22 \pm 2 \mathrm{~g}$ ) were subcutaneously injected with $100 \mu \mathrm{l}$ of the cell suspension $\left(5 \times 10^{7}\right.$ cells $/ \mathrm{ml}$ in PBS) in the mid-back region. Tumor xenograft formation was measured every two days in order to record the growth curves. Two weeks after the injection, 8 mice per group were sacrificed. Tumor xenografts and lung tissues were surgically dissected and then fixed with $4 \%$ formaldehyde in PBS and embedded in paraffin. Sections were stained with hematoxylin and eosin (H\&E). Tumor xenografts were weighed and measured. Tumor volume was calculated according to the equation $\mathrm{LxW}^{2} / 2$ with the length (L) (mm) being the longer axis of the tumor. The muscle infiltration and lung metastasis was observed according to the (H\&E) staining. The remaining mice were maintained for 60 days to determine the survival rate. The experiments were carried out in accordance with recommendations cited in the Guide for the Care and Use of Laboratory Animals of the Medical Laboratory Animal Center of Guangdong Province, China; permit number SCXK2008-0002.

RT-PCR analysis. Total RNA was isolated from the F9 cells using TRIzol (Invitrogen). Total RNA $(2 \mu \mathrm{g})$ was reverse transcribed using $1 \mu \mathrm{g}$ oligo(dT) primer with MMLV reverse transcriptase (Promega) in a $40-\mu 1$ reaction volume containing $1.25 \mathrm{mM}$ deoxyribonucleoside triphosphates (dNTPs) at $42^{\circ} \mathrm{C}$. PCR primers of TCF3, Oct4 and actin were designed using the PrimerSelect program from the DNASTAR software package (DNASTAR Inc., Madison, WI). PCR was performed using $1 \mu \mathrm{l}$ of cDNA in a $25-\mu \mathrm{l}$ PCR mixture containing 15 pmol of each primer, $0.1 \mathrm{mM}$ dNTP and 0.3 units Taq polymerase (Promega). The PCR products were electrophoresed on $1.5 \%$ ethidium bromide-stained agarose gel and observed under a UV transilluminator. Primers were as 
A

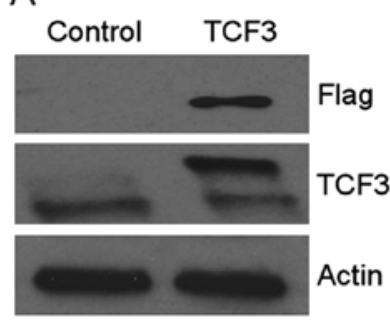

D

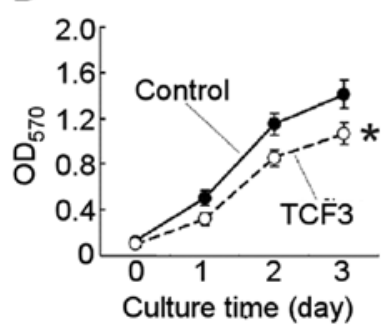

B

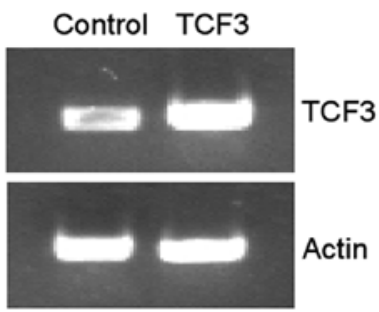

E

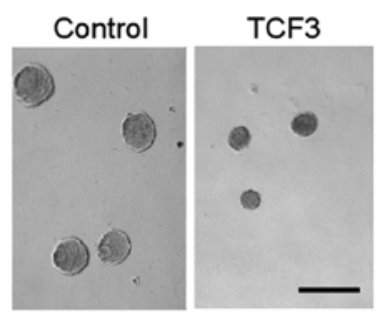

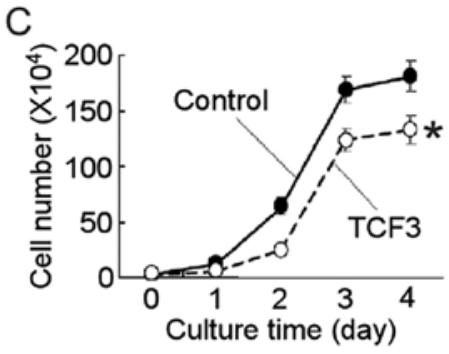

F

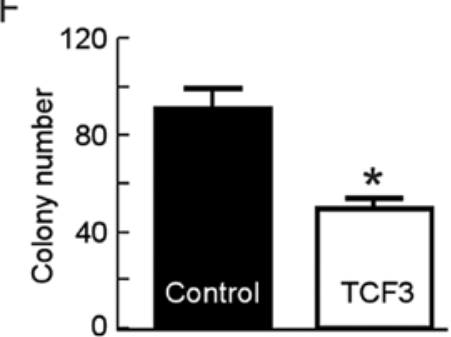

Figure 1. TCF3 inhibits F9 EC cell growth, proliferation and colony formation. (A) TCF3 protein expression was determined by immunoblotting using antibodies against fusion protein tag Flag and TCF3 respectively. Actin was used as a reference protein. F9 cells infected with virus packaged from the empty vector pMSCV-3Flag-3HA were used as a control. (B) TCF3 mRNA expression was detected in F9-TCF3 and F9-control EC cells by RT-PCR analysis. (C) TCF3 inhibited the growth of F9 cells. Cells were counted using a hemocytometer at days 1,2,3 and 4 after being seeded in 6-well plates. Values are means \pm SD, n=6; ${ }^{*} \mathrm{P}<0.01$. (D) TCF3 inhibited F9 cell proliferation measured by the MTT assay. The proliferation rates are shown as $\mathrm{OD} 570 .{ }^{\text {Values }}$ are means $\pm \mathrm{SD}, \mathrm{n}=6$; ${ }^{*} \mathrm{P}<0.01$. (E) Representative images of colonies; scale bar, $400 \mu \mathrm{m}$. (F) TCF3 inhibited the colony formation of F9 cells. Values are means \pm SD, $\mathrm{n}=6$; ${ }^{*} \mathrm{P}<0.01$.

follows: TCF3, 5'-TGAGAAGCCTTGTGATAGCC-3' (sense) and 5'-GAGACAGCCTGCATAGAACC-3' (antisense); Oct4, 5'-TCTTTCCACCAGGCCCCCGGCTC-3' (sense) and 5'-TGC GGGCGGACATGGGGAGATCC-3' (antisense); actin, 5'-TCC AGCCTTCCTTCTTGGGTATG-3' (sense) and 5'-GAAGGT GGACAGTGAGGCCAGGAT-3' (antisense).

Immunoblot analysis. Cells were lysed in NP-40 lysis buffer containing $50 \mathrm{mM}$ Tris (pH 7.4), $150 \mathrm{mM} \mathrm{NaCl}, 1 \%$ NP-40, $20 \mu \mathrm{g} / \mathrm{ml}$ PMSF, $1 \mu \mathrm{g} / \mathrm{ml}$ pepstatin A and $1 \mu \mathrm{g} / \mathrm{ml}$ leupeptin (pH 7.4). Tumor tissue was homogenized in $250 \mathrm{mM}$ sucrose containing $1 \mathrm{mM}$ EDTA, $20 \mu \mathrm{g} / \mathrm{ml}$ PMSF, $1 \mu \mathrm{g} / \mathrm{ml}$ pepstatin A and $1 \mu \mathrm{g} / \mathrm{ml}$ leupeptin ( $\mathrm{pH}$ 7.4) with a glass Dounce homogenizer. Total protein was assayed using a Bio-Rad DC protein assay kit (Bio-Rad). Proteins $(15 \mu \mathrm{g})$ were electrophoresed through $10 \%$ (w/v) polyacrylamide, 1\% (w/v) SDS gels. Proteins were transferred from the gels by blotting onto a nitrocellulose membrane (Millipore). The membranes were blocked with $0.02 \mathrm{~mol} / 1$ Tris- $\mathrm{HCl}$ (pH 7.0), $0.9 \%$ (w/v) $\mathrm{NaCl}$, $0.1 \%(\mathrm{v} / \mathrm{v})$ Tween-20 containing 5\% (w/v) non-fat milk for $1 \mathrm{~h}$ at room temperature. Monoclonal antibodies anti-Oct4 (1:2000; Santa Cruz Biotechnology), anti-PCNA (1:2000; Santa Cruz Biotechnology), anti-Flag (1:1000; Sigma) or anti-TCF3 (1:200; Santa Cruz Biotechnology) were added and incubation was carried out overnight at $4^{\circ} \mathrm{C}$. Bound antibodies were located by a further incubation with horseradish peroxidase-conjugated goat anti-mouse IgG (1:5000; Santa Cruz Biotechnology). As a loading control, the membranes were immunoblotted for $\beta$-actin (1:500; Santa Cruz Biotechnology). Blots were developed with an ECL Plus kit (Pierce) and exposed to Kodak film. The National Institutes of Health Image program was used to quantify the intensity of the resulting bands.
Statistical analysis. All data are presented as the mean \pm SD. The results were compared by one-way analysis of variance (ANOVA). All statistical calculations were performed with the SPSS11.0 software package. A P-value $<0.05$ was regarded as statistically significant.

\section{Results}

TCF3 inhibits F9 EC cell proliferation and colony formation. RT-PCR assay confirmed the overexpression of TCF3 mRNA in the pMSCV-3Flag-3HA-TCF3-infected F9 EC cells (Fig. 1A). Endogenous TCF3 protein $(79 \mathrm{kDa})$ and exogenous TCF3 protein $(85 \mathrm{kDa})$ were detected by immunoblot analysis using anti-Flag or anti-TCF3 antibodies (Fig. 1B). The results showed that the TCF3 protein level in the pMSCV-3Flag-3HA-TCF3-infected F9 EC cells was significantly higher than that in the pMSCV-3Flag-3HA-infected F9 EC cells.

The effect of exogenous overexpressed TCF3 on F9 cell proliferation was monitored over a 5-day period by counting the number of cells. The number of F9-TCF3 cells was significantly lower (by 34\%) than that of the F9-control cells $(\mathrm{P}<0.01)$ (Fig. 1C). The MTT cell proliferation assay revealed that the rate of proliferation of the TCF3-overexpressing cells decreased $\sim 30 \%$ compared with that of the F9-control cells (Fig. 1D). The soft agar colony assay demonstrated that the size of the colonies in the F9-TCF3 cells was significantly smaller (by $45 \%, \mathrm{P}<0.01$ ) than that in the F9-control cells (Fig. 1E). The number of colonies in the F9-TCF3 cells was significantly lower than that in the F9-control cells (Fig. 1F). These results suggest that TCF3 overexpression inhibits the proliferation of F9 EC cells. 
A

Control
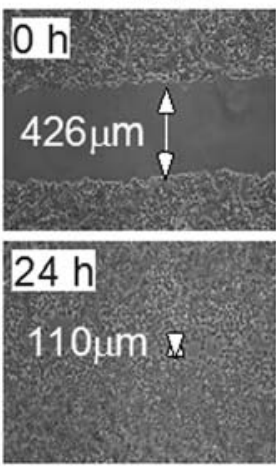

TCF3
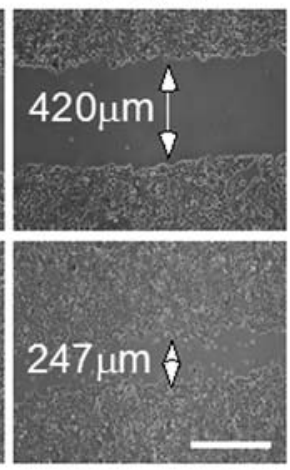

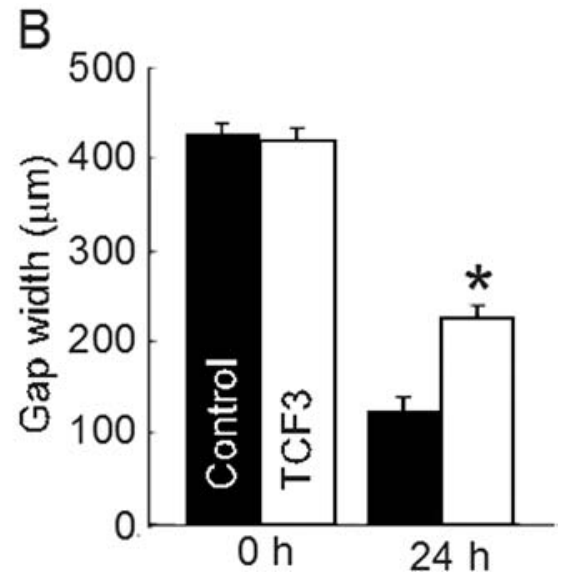

Figure 2. TCF3 inhibits F9 EC cell migration. (A) Representative images of F9 cell migration determined at 0 and $24 \mathrm{~h}$ by measuring the width of the gap produced by scraping of the cell monolayer with a 200- $\mu \mathrm{m}$ micropipette tip; scale bar, $400 \mu \mathrm{m}$. (B) Gap distances were microscopically measured and statistically analyzed. Values are the means $\pm \mathrm{SD}, \mathrm{n}=3 ;{ }^{*} \mathrm{P}<0.01$.

A

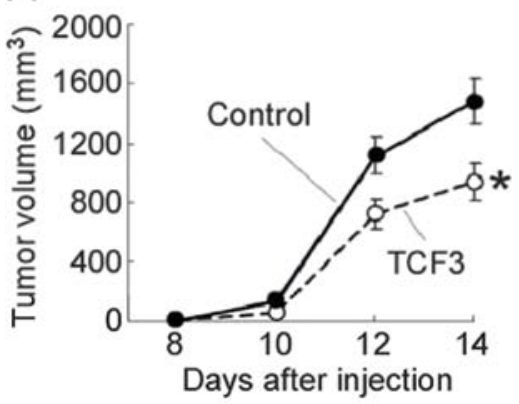

C

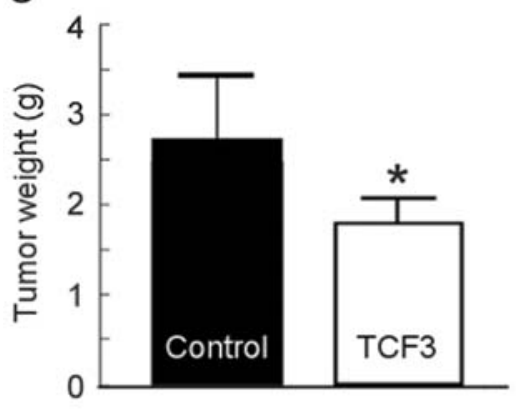

E

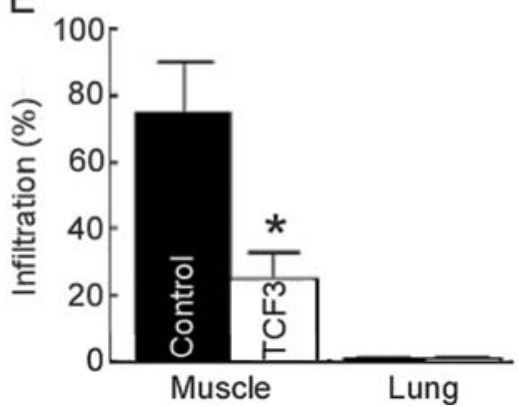

B

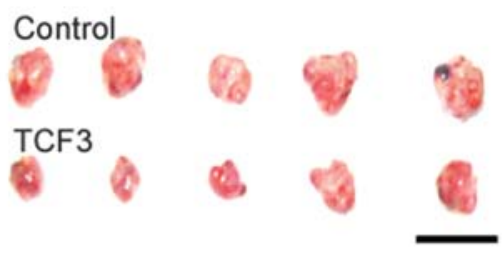

D

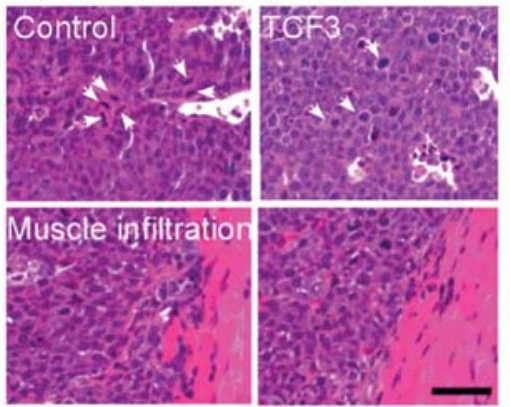

F

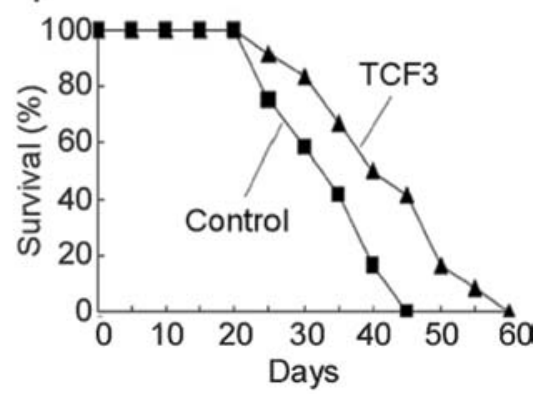

Figure 3. TCF3 inhibits xenograft tumor growth and prolongs the survival of tumor-bearing mice. (A) TCF3 inhibited tumor mass growth in mice bearing tumors derived from F9 cells. Tumors were measured in three dimensions on the indicated days after injection. Values are the means $\pm \mathrm{SD}$, $=8 ;{ }^{*} \mathrm{P}<0.01$. (B) Representative images of tumors derived from both F9-control and F9-TCF3 cell implantation. F9-control cells (5x10 6 ) (control) or F9-TCF3 cells (TCF3) were injected subcutaneously into the mid-back area of adult BALB/C mice. Tumors were excised on day 15 after injection. Scale bar, 30 mm. (C) Weight of xenograft tumors on day 15 post-injection. Values are the means $\pm \mathrm{SD}, \mathrm{n}=8 ;{ }^{*} \mathrm{P}<0.05$. (D) Hematoxylin and eosin (H\&E) staining indicating abnormal mitoses (arrow) and local muscle infiltration in xenograft tumors derived from TCF3-overexpressing cells compared with the tumors derived from the F9-control cells. Scale bar, $100 \mu \mathrm{m}$. (E) Local infiltration and lung metastasis in mouse tumors derived from F9-control or TCF3-overexpressing cells. Values are the means $\pm \mathrm{SD}, \mathrm{n}=3 ;{ }^{*} \mathrm{P}<0.01$. (F) Survival curve of the tumor-bearing mice. 
A

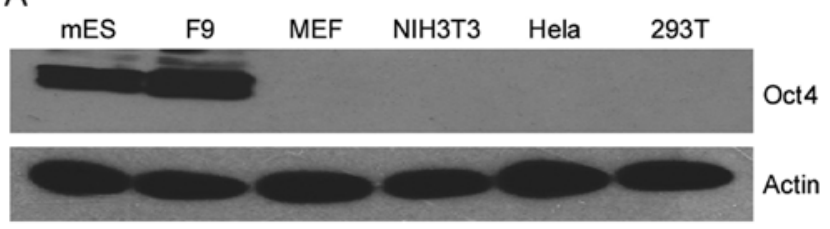

B
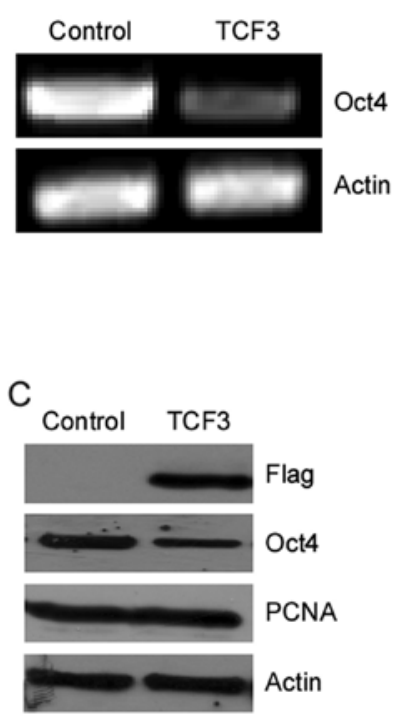
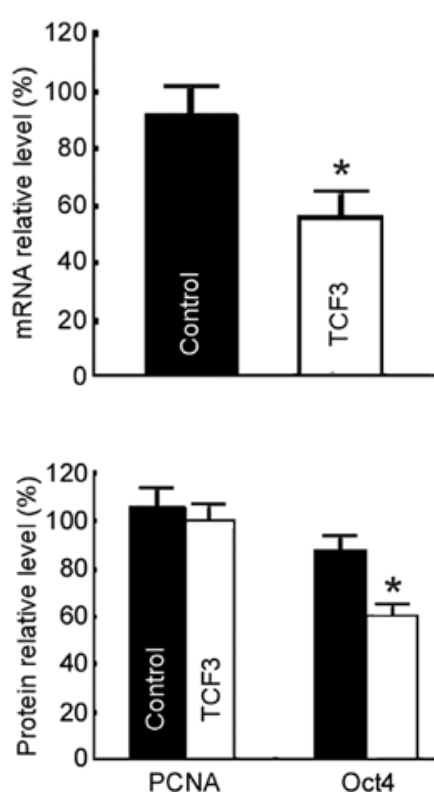

Figure 4. TCF3 down-regulates Oct4 expression in F9 EC cells. (A) Immunoblot analysis of Oct4 expression in the different cell lines. F9 EC and mES cells expressed abundant Oct 4 protein. Actin was probed with an anti-actin antibody as a reference protein. (B) TCF3 down-regulated the Oct 4 mRNA expression determined by RT-PCR analysis. Actin was used as a control Values are the means $\pm \mathrm{SD}, \mathrm{n}=3 ;{ }^{*} \mathrm{P}<0.01$. (C) TCF3 and Oct4 expression in a xenograft tumor. Actin and PCNA were probed as reference proteins. Values are the means $\pm \mathrm{SD}, \mathrm{n}=3 ;{ }^{*} \mathrm{P}<0.01$.

TCF3 inhibits the migration of F9 cells. In order to observe the effect of TCF3 on cell migration, F9-TCF3 and F9-control cells were seeded in 6-well plates. After forming a monolayer, cells were wounded by manual scraping to produce a gap. With continuous incubation, the gap was filled by migrating cells near to the gap. Notably, $24 \mathrm{~h}$ later, the gap in the F9-TCF3 cells was significantly wider $(227.83 \pm 24.27 \mu \mathrm{m})$ than that in the F9-control cells $(122.96 \pm 12.18 \mu \mathrm{m})(\mathrm{P}<0.01)$ (Fig. 2), indicating that overexpression of TCF3 decreases the migratory ability of F9 EC cells.

TCF3 inhibits the growth and infiltration of xenograft tumors in vivo. To determine the tumor suppressive ability of TCF3 in vivo, F9-control or F9-TCF3 cells were subcutaneously injected into $\mathrm{BALB} / \mathrm{C}$ mice, respectively. After injection, tumor growth was monitored for 15 days. Tumor growth was significantly inhibited by TCF3 as shown in Fig. 3A. On day 15 , the tumor volume and weight of the xenograft tumors derived from the TCF3-overexpressing cells were significantly different than the tumor volume and weight of the xenograft tumors derived from the F9-control cells (Fig. 3B and $\mathrm{C})(\mathrm{P}<0.05)$. Tissue morphological analysis demonstrated that fewer abnormal mitoses, which are a typical marker of

malignancy, were noted in the TCF3 group compared with that in the control group (Fig. 3D). Consistently, TCF3 also decreased the local infiltration of the tumors. Local muscle infiltration was noted in $\sim 75 \%$ of the control mice and in $\sim 25 \%$ of the TCF3 group mice, respectively (Fig. 3E). No lung metastasis was found in either group (Fig. 3E).

As TCF3 may serve as an inhibitory factor for tumor growth and infiltration, the life span of the tumor-bearing mice was determined. Notably, TCF3 prolonged the life span of the tumor-bearing mice (Fig. 3F). These results consistently confirmed that TCF3 inhibits F9 EC cell growth, proliferation, migration and xenograft tumor growth and infiltration.

TCF3 down-regulates Oct4 in F9 cells and its derived tumors. To investigate the mechanism of the antitumor-like activity of TCF3, the expression of stem character gene Oct4 was determined in various cell lines. As showed in Fig. 4A, Oct4 was abundantly expressed in the mES and F9 EC cells. Oct4 was not detected in MEF, NIH3T3, 293T somatic cells or in the HeLa tumor cell line (Fig. 4A). Oct4 mRNA expression was significantly down-regulated in the TCF3-expressing F9 cells (Fig. 4B). Oct4 protein expression was significantly down-regulated in the xenograft tumor masses derived from the F9-TCF3 cells when compared to the tumors derived from the F9-control cells. However, the expression levels of the unrelated endogenous protein PCNA and Actin were not different between the groups (Fig. 4C).

\section{Discussion}

TCF3 is a critical component of the Wnt pathway. TCF3 possesses a highly conserved $\beta$-catenin binding domain and has been suggested to promote target gene transcription as a $\beta$-catenin-dependent activator and to down-regulate gene transcription as a $\beta$-catenin-independent repressor $(6,16,17)$. Of the TCFs, TCF3 is the most abundantly expressed in ES cells and participates in many physiological regulatory and developmental processes (16-20).

Previous studies involving mES cells showed that TCF3 null mES cells can proliferate and self-renew in the absence of LIF and delay differentiation in embryoid bodies (14). It has been suggested that ablation of TCF3 in mES cells stimulates cell proliferation by activating Jak/Stat3 activity (15). Although many similar biochemical properties exist between EC and ES cells, the role of TCF3 in the development of EC tumors remains unknown. Our results showed that overexpression of TCF3 significantly inhibited the proliferation and tumorigenic phenotype of F9 EC cells in vitro. In vivo experiments confirmed that subcutaneously injected F9 EC cells overexpressing TCF3 formed smaller and less malignant tumors. Thus, we hypothesized that TCF3 controls the proliferation and differentiation of EC cells by regulating certain intracellular signaling pathways.

Oct4 expression was found to be down-regulated in TCF3-overexpressing EC tumors. Oct4, which is a member of the mammalian POU family of transcriptional factors, functions as a key regulator of the self-renewal and pluripotency of ES cells (21-23). Oct4 has been frequently reported to reprogram somatic cells into pluripotent stem cells (iPS) together with Sox-2, c-Myc and Klf4 (24-28). Furthermore, 
Oct4 introduction was found to be sufficient to result in the direct reprogramming of human neural stem cells (29). Apart from ES cells, Oct4 was found to be expressed in cancer stem cell-like cells. The ablation of Oct 4 by small interfering RNA was found to eventually result in cell apoptosis, and the signal pathway Oct4/Tcl1/Akt1 has been suggested to be involved in this event $(30,31)$.

However, Oct4 was found to up-regulate fibroblast growth factor-4 and matrix metalloproteinase-2 (MMP-2), MMP-9 and MMP-13 in clinical bladder tumors. Tumors with intense Oct4 expression were associated with further disease progression, a greater degree of metastasis and shorter cancer-related survival compared with those with moderate and low Oct4 expression (32), as revealed in our study. Nanog and Sox2 are another two key regulators in the process of pluripotency maintenance $(33,34)$. Oct 4 and Sox 2 comprise a regulatory complex that regulates many genes important for the maintenance of the primitive state $(35,36)$. Endogenous Oct 4 and the Oct4/Sox 2 complex bind to the Nanog, Oct4 and Sox 2 gene regulatory elements in F9 cell (37). Thus Oct4 downregulation affects the genes controlling self renewal such as Nanog, and subsequently induces apoptotic cell death (38). All of these regulations may inhibit the growth of EC tumors.

Oct4 was down-regulated in TCF3-overexpressing EC cells, but how TCF3 executes this biological function in EC cells is still obscure. In mES cells, TCF3 normally interacts with TLE2, a WD40 repeat protein. One possibility is that TCF3 interacts with TLE2 to co-repress Oct4 transcription directly. In addition, TLE2 binds to the CUL4-DDB1 ubiquitin E3 ligase core complex (39). Therefore, it is also possible that TLE2 destabilizes a critical protein which is targeted by Oct4 for ubiquitin-dependent proteolysis by the CUL4-DDB1 ubiquitin E3 ligase.

\section{Acknowledgements}

This study was supported by grants from the National Natural Science Foundation of China (NSFC) (nos. 3030231 and 30870921) and grants from the Science and Technology Bureau of Shezhen, and the Science and Technology Department of Jilin Province (no. 201015195).

\section{References}

1. Andrews PW, Matin MM, Bahrami AR, Damjanov I, Gokhale P and Draper JS: Embryonic stem (ES) cells and embryonal carcinoma (EC) cells: opposite sides of the same coin. Biochem Soc Trans 33: 1526-1530, 2005.

2. Boyer LA, Lee TI, Cole MF, et al: Core transcriptional regulatory circuitry in human embryonic stem cells. Cell 122: 947-956, 2005.

3. Logan CY and Nusse R: The Wnt signaling pathway in development and disease. Annu Rev Cell Dev Biol 20: 781-810, 2004.

4. Reya T, Duncan AW, Ailles L, et al: A role for Wnt signalling in self-renewal of haematopoietic stem cells. Nature 423: 409-414, 2003.

5. Sato N, Meijer L, Skaltsounis L, Greengard P and Brivanlou AH: Maintenance of pluripotency in human and mouse embryonic stem cells through activation of Wnt signaling by a pharmacological GSK-3-specific inhibitor. Nat Med 10: 55-63, 2004.

6. Brannon M, Gomperts M, Sumoy L, Moon RT and Kimelman D: A beta-catenin/XTcf-3 complex binds to the siamois promoter to regulate dorsal axis specification in Xenopus. Genes Dev 11: 2359-2370, 1997.
7. Van de Wetering M, Cavallo R, Dooijes D, et al: Armadillo coactivates transcription driven by the product of the Drosophila segment polarity gene dTCF. Cell 88: 789-799, 1997.

8. Brannon M, Brown JD, Bates R, Kimelman D and Moon RT: $\mathrm{XCtBP}$ is a XTcf-3 co-repressor with roles throughout Xenopus development. Development 126: 3159-3170, 1999.

9. Brantjes H, Roose J, van de Wetering $M$ and Clevers H: All Tcf HMG box transcription factors interact with Groucho-related co-repressors. Nucleic Acids Res 29: 1410-1419, 2001.

10. Cavallo RA, Cox RT, Moline MM, et al: Drosophila Tcf and Groucho interact to repress Wingless signalling activity. Nature 395: 604-608, 1998

11. Roose J, Molenaar M, Peterson J, et al: The Xenopus Wnt effector XTcf-3 interacts with Groucho-related transcriptional repressors. Nature 395: 608-612, 1998.

12. Tam WL, Lim CY, Han J, et al: T-cell factor 3 regulates embryonic stem cell pluripotency and self-renewal by the transcriptional control of multiple lineage pathways. Stem Cells 26: 2019-2031, 2008

13. Cole MF, Johnstone SE, Newman JJ, Kagey MH and Young RA: Tcf3 is an integral component of the core regulatory circuitry of embryonic stem cells. Genes Dev 22: 746-755, 2008.

14. Yi F, Pereira L and Merrill BJ: Tcf3 functions as a steady-state limiter of transcriptional programs of mouse embryonic stem cell self-renewal. Stem Cells 26: 1951-1960, 2008.

15. Yi F and Merrill BJ: Non-cell-autonomous stimulation of stem cell proliferation following ablation of Tcf3. Exp Cell Res 316: 1050-1060, 2010

16. Merrill BJ, Gat U, DasGupta R and Fuchs E: Tcf3 and Lef1 regulate lineage differentiation of multipotent stem cells in skin. Genes Dev 15: 1688-1705, 2001.

17. Nguyen H, Merrill BJ, Polak L, et al: Tcf3 and Tcf4 are essential for long-term homeostasis of skin epithelia. Nat Genet 41: 1068-1075, 2009

18. Dorsky RI, Itoh M, Moon RT and Chitnis A: Two tcf3 genes cooperate to pattern the zebrafish brain. Development 130: 1937-1947, 2003

19. Lee E, Salic A and Kirschner MW: Physiological regulation of beta-catenin stability by Tcf3 and CKlepsilon. J Cell Biol 154: 983-993, 2001.

20. Nguyen H, Rendl M and Fuchs E: Tcf3 governs stem cell features and represses cell fate determination in skin. Cell 127: 171-183, 2006.

21. Nichols J, Zevnik B, Anastassiadis K, et al: Formation of pluripotent stem cells in the mammalian embryo depends on the POU transcription factor Oct4. Cell 95: 379-391, 1998.

22. Niwa H, Miyazaki J and Smith AG: Quantitative expression of Oct-3/4 defines differentiation, dedifferentiation or self-renewal of ES cells. Nat Genet 24: 372-376, 2000.

23. Nishiyama A, Xin L, Sharov AA, et al: Uncovering early response of gene regulatory networks in ESCs by systematic induction of transcription factors. Cell Stem Cell 5: 420-433, 2009.

24. Okita K, Ichisaka T and Yamanaka S: Generation of germlinecompetent induced pluripotent stem cells. Nature 448: 313-317, 2007.

25. Takahashi K, Tanabe K, Ohnuki M, et al: Induction of pluripotent stem cells from adult human fibroblasts by defined factors. Cell 131: 861-872, 2007.

26. Takahashi $\mathrm{K}$ and Yamanaka S: Induction of pluripotent stem cells from mouse embryonic and adult fibroblast cultures by defined factors. Cell 126: 663-676, 2006.

27. Wernig M, Meissner A, Foreman R, et al: In vitro reprogramming of fibroblasts into a pluripotent ES-cell-like state. Nature 448: 318-324, 2007.

28. Yu J, Vodyanik MA, Smuga-Otto K, et al: Induced pluripotent stem cell lines derived from human somatic cells. Science 318: 1917-1920, 2007.

29. Kim JB, Greber B, Arauzo-Bravo MJ, et al: Direct reprogramming of human neural stem cells by OCT4. Nature 461: 649-643, 2009.

30. Hu T, Liu S, Breiter DR, Wang F, Tang Y and Sun S: Octamer 4 small interfering RNA results in cancer stem cell-like cell apoptosis. Cancer Res 68: 6533-6540, 2008.

31. Matoba R, Niwa H, Masui S, et al: Dissecting Oct3/4-regulated gene networks in embryonic stem cells by expression profiling. PLoS One 1: e26, 2006.

32. Chang CC, Shieh GS, Wu P, Lin CC, Shiau AL and Wu CL: Oct-3/4 expression reflects tumor progression and regulates motility of bladder cancer cells. Cancer Res 68: 6281-6291, 2008. 
33. Chambers I and Tomlinson SR: The transcriptional foundation of pluripotency. Development 136: 2311-2322, 2009.

34. Medvedev SP, Shevchenko AI, Mazurok NA and Zakiian SM: OCT4 and NANOG are the key genes in the system of pluripotency maintenance in mammalian cells. Genetika 44: 1589-1608, 2008.

35. Okumura-Nakanishi S, Saito M, Niwa H and Ishikawa F: Oct-3/4 and Sox 2 regulate Oct-3/4 gene in embryonic stem cells. J Biol Chem 280: 5307-5317, 2005.

36. Wang ZX, Teh CH, Kueh JL, Lufkin T, Robson P and Stanton LW: Oct 4 and Sox 2 directly regulate expression of another pluripotency transcription factor, Zfp206, in embryonic stem cells. J Biol Chem 282: 12822-12830, 2007.
37. Kuroda T, Tada M, Kubota H, et al: Octamer and Sox elements are required for transcriptional cis regulation of Nanog gene expression. Mol Cell Biol 25: 2475-2485, 2005.

38. Yamaguchi S, Kurimoto K, Yabuta Y, et al: Conditional knockdown of Nanog induces apoptotic cell death in mouse migrating primordial germ cells. Development 136: 4011-4020, 2009.

39. Higa LA, Wu M, Ye T, Kobayashi R, Sun $H$ and Zhang $H$ : CUL4-DDB1 ubiquitin ligase interacts with multiple WD40repeat proteins and regulates histone methylation. Nat Cell Biol 8: 1277-1283, 2006. 